\title{
Meniscus Regeneration With Multipotent Stromal Cell Therapies
}

\author{
Yun-Feng Zhou ${ }^{1,2 \dagger}$, Di Zhang ${ }^{3 \dagger}$, Wan-Ting Yan ${ }^{2,4}$, Kai Lian ${ }^{1 *}$ and Zheng-Zheng Zhang ${ }^{2 *}$ \\ ${ }^{1}$ Department of Orthopedics, Xiangyang No. 1 People's Hospital, Hubei University of Medicine, Xiangyang, China, ${ }^{2}$ Department of \\ Orthopedics, Sun Yat-sen Memorial Hospital, Sun Yat-sen University, Guangzhou, China, ${ }^{3}$ Department of Obstetrics- \\ Gynecology, Xiangyang No.1 People's Hospital, Hubei University of Medicine, Xiangyang, China, ${ }^{4}$ School of Medicine, Sun Yat- \\ sen University, Shenzhen, China
}

\section{OPEN ACCESS}

Edited by:

Dong Jiang,

Peking University Third Hospital, China

Reviewed by:

Jehan J. El-Jawhari,

Nottingham Trent University, United Kingdom

Vahid Serpooshan,

Emory University, United States

Andreas Martin Seitz,

Ulm University Medical Center,

Germany

Goutam Thakur,

Manipal Institute of Technology, India

*Correspondence:

Zheng-Zheng Zhang z7z1985114@163.com

Kai Lian

yfzhou0506@163.com

${ }^{t}$ These authors have contributed equally to this work

Specialty section:

This article was submitted to Biomaterials,

a section of the journal

Frontiers in Bioengineering and

Biotechnology

Received: 16 October 2021

Accepted: 11 January 2022

Published: 09 February 2022

Citation:

Zhou Y-F, Zhang D, Yan W-T, Lian K and Zhang Z-Z (2022) Meniscus Regeneration With Multipotent Stromal

Cell Therapies.

Front. Bioeng. Biotechnol. 10:796408. doi: 10.3389/fbioe.2022.796408
Meniscus is a semilunar wedge-shaped structure with fibrocartilaginous tissue, which plays an essential role in preventing the deterioration and degeneration of articular cartilage. Lesions or degenerations of it can lead to the change of biomechanical properties in the joints, which ultimately accelerate the degeneration of articular cartilage. Even with the manual intervention, lesions in the avascular region are difficult to be healed. Recent development in regenerative medicine of multipotent stromal cells (MSCs) has been investigated for the significant therapeutic potential in the repair of meniscal injuries. In this review, we provide a summary of the sources of MSCs involved in repairing and regenerative techniques, as well as the discussion of the avenues to utilizing these cells in MSC therapies. Finally, current progress on biomaterial implants was reviewed.

Keywords: mesenchymal stem cell, meniscus repair, regenerative medicine, tissue engineering, biotherapy

\section{INTRODUCTION}

Located between the femoral condyle and tibia plateau cartilage in the knee joint, meniscus is a crescent-shaped fibrocartilaginous tissue. This semilunar disk decreases the stress of the tibiofemoral joint by increasing the congruency and the contact area of it (Englund et al., 2012). It also serves as a shock absorber and secondary stabilizer with a possible role in joint lubrication and proprioception (Makris et al., 2011). It has been reported that the meniscus is highly heterogeneous in cellular and extracellular matrix composition, as well as biomechanical properties (Morejon et al., 2020). The structural integrity and biological function would be impaired due to meniscus lesion, which ultimately lead to the deterioration of the joint and accelerate the development of osteoarthritis for the excessive concentrated forces adding on the articular cartilage (Danso et al., 2017).

Due to the differences in its blood supply and cell composition, the internal tissue composition of the healed meniscus was changed and could not be restored to the original state, especially in its relatively hypocellular and hypovascular inner edge. Currently, the prevailing theory for the treatment of meniscusrelated lesions is to preserve its integrity as much as possible. Repair of the meniscal tear with a suture is a commonly used method (Chen et al., 2018; Zhang et al., 2020). However, the reported failure rates ranged from 0 to $38 \%$ for inside-out repairs and reached $\sim 80 \%$ for all-inside suture techniques (Barber-Westin and Noyes, 2014; Zhang et al., 2020). For patients with a large area of meniscus deficiency or widespread degeneration, meniscal allograft could be transplanted to maintain the function. It can effectively enhance objective knee stability and insignificantly narrow the joint space with a 5-year follow-up (Saltzman et al., 2017). However, this operation often requires the removal of the whole meniscus, including the remaining normal tissue. Drilling of extra bone tunnels is also needed for fixation, which is a more complex procedure with small incisions. Furthermore, the donor-matching process and the procurement of the 


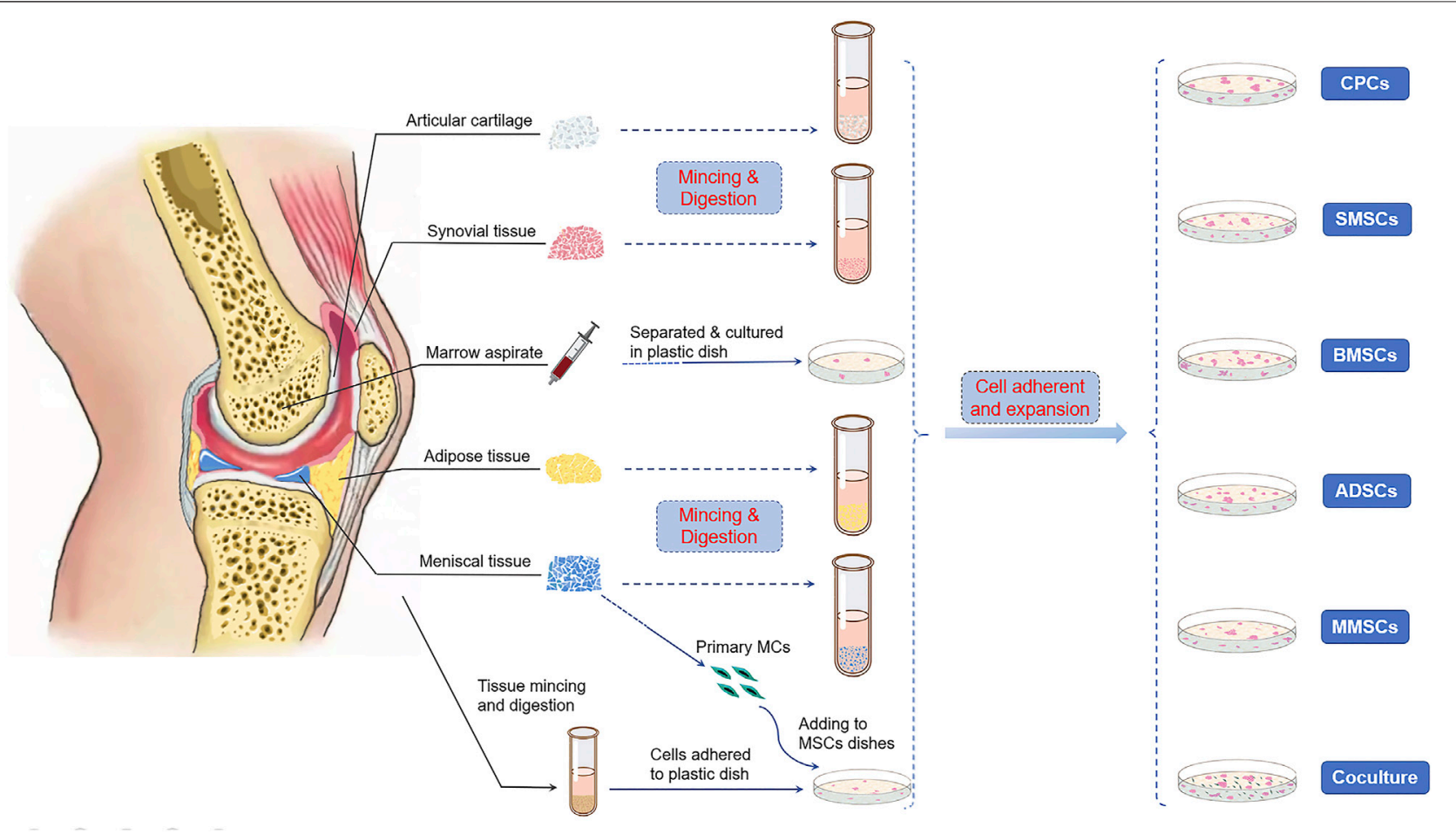

FIGURE 1 | Cell sources of multipotent stromal cells (MSCs) in meniscus repair and regeneration. Bone marrow, synovium, cartilage, adipose tissue, and the meniscus itself were reported to be able to isolate stem/progenitor cells. Primary meniscus cells (MCs) also cocultured with MSCs from other tissues to induce directional differentiation.

graft before the surgery should also be taken into consideration. The transplantation of live cells in the allograft also carries the risks of disease transmission and the activation of immune response (Kurzweil et al., 2018165). In recent years, the newly developing regenerative medicine techniques have provided new hope for the treatment of damaged tissues. Regenerative medicine with MSCs has been receiving a growing attention in meniscal repair for their abilities of self-renew and multilineage differentiation (Pabbruwe et al., 2010; Embree et al., 2016).

With highly proliferative capacity, MSCs have been proven to be reliable cell sources for meniscus repair in clinical and preclinical studies. These cells differentiate into mature cells in the targeted tissue and generate an extracellular matrix so as to reconnect the damaged region or form new tissue, and display a similar morphology and function with adjacent tissue (Cossu et al., 2018). Several materials have been studied for their meniscal regenerative efficacy, whether absorbable or nonabsorbable, natural, or synthetic (Zhang et al., 2015). Two kinds of techniques have been developed in meniscus regenerative medicine: cell-based and cell-free. While the former attempts to use scaffolds seeded with MSCs, the latter tends to implant scaffold into the joint without cells, repairing the meniscus by recruiting endogenous MSCs (Guo et al., 2018). In general, meniscus regeneration strategies using various MSC sources have been well documented in the literature, which can possibly provide a new strategy for meniscus repair (Twomey-Kozak and Jayasuriya, 2020; Dai et al., 2021). Nevertheless, a huge challenge still lies in mimicking its natural anisotropic structure. According to the published researches, the repair of meniscus defect is mostly regenerated with a homogeneous structure, which could not completely restore its function (Zhang et al., 2019; Li et al., 2021).

In this review, we generalized the sources of MSCs and descripted their biochemical characteristics and general situation. We also give a brief introduction to the MSCs utilizing approaches in meniscus regeneration. Both cell-based and cell-free strategies as well as one- or two-step methods will be involved in our discussion.

\section{MSC SOURCES}

MSCs could be obtained from various musculoskeletal tissues, such as bone marrow, synovium, adipose, cartilage, vessel, tendon, muscle, and meniscus itself. The International Society for Cellular Therapy (ISCT) put forward the criteria to define human MSCs (Dominici et al., 2006): expressing CD105, CD73, and CD90, and lack expression of CD45, CD34, CD14 or CD11b, CD79a or CD19, and HLA-DR surface molecules; besides, it must be plastic-adherent when maintained in a standard culture condition and preserve the ability of trilineage differentiation when incubated in an induced medium. In this section, we will focus on the 
application of various MSCs and their repair/regeneration efficacy for meniscus regeneration (Figure 1).

\subsection{Bone Marrow Stem Cell}

BMSCs are one of the most extensively studied and the most commonly explored source for tissue regeneration. Surface markers CD271, CD146, CD90 (Thy1), CD106 (VCAM1), CD105, CD51 (integrin a5), and CD140a (PDGFRa, also known as PDGF receptor $\alpha$ ) have been shown to express its molecular detection and identification (Isern et al., 2013; Mabuchi et al., 2013). It is worth mentioning that the latter two markers were only detected in fetal BMSCs (Pinho et al., 2013). The key mechanism for the successful repair using BMSCs is the formation of ECM and its connection with surrounding normal tissues in the defect zone. The trophic factors secreted by these cells, which possibly can recruit resident cells, also contribute to this process (Caplan and Dennis, 2006). However, several drawbacks hinder the application of BMSCs. First, with less than $0.02 \%$ of bone marrow cells being BMSCs, the quantity is relatively limited (Alvarez-Viejo et al., 2013). Second, BMSCs are prone to develop into hypertrophic cells in cellular culture or tissue regenerative studies (Bilgen et al., 2018). Third, the operation of cell harvesting increases the risk of pain-suffering, infection, and morbidity of the donor site (Ma et al., 2018). What is more, the regenerative ability of BMSCs is largely dependent on the age of the donor: cells derived from the elder usually show weaker proliferation and differentiation capabilities.

\subsection{Synovium-Derived Mesenchymal Stem Cell}

In the early 21st century, SMSC was first isolated from the synovial membrane surrounding the joints. Due to its outstanding chondrogenic differentiation ability, it has received growing attention in recent years (Horie et al., 2012b; Nakagawa et al., 2015; Kondo et al., 2017). Compared with BMSCs, the SMSCs show greater colony-forming ability. It is reported that in SMSCs, 1 colony could be formed in 12.5-80 nucleated cells compared with 1 in $10^{3}-10^{4}$ in BMSCs (Jo et al., 2007). SMSCs express CD105, CD73, CD140b, SSEA3, CD271, CD90, CD44, and CD34 (Matsumura et al., 2017). CD271 is a marker related to the differentiation potential, and the number of CD271-positive SMSCs increased in the expansion culture in vitro (Del Rey et al., 2016). Besides, CD90 was also highly expressed in SMSCs, which might be strongly correlated with the great chondrogenic potential of SMSCs retained over four passages (Sakaguchi et al., 2005; Roche et al., 2009). Meanwhile, the production of osteocalcin and alkaline phosphatase (ALP) in the SMSC group was nearly 10-fold lower than that of the BMSC group (Roche et al., 2009), which partially explains the finding that BMSCs are more prone to osteogenesis, while SMSCs incline to chondrogenesis. Treatment with SMSC transplantation also showed a protective effect on articular cartilage in aged cynomolgus macaque models (Kondo et al., 2017). Additionally, unlike BMSCs, the proliferation rate of SMSCs could be maintained regardless of age, and this superior character provides exciting news for tissue regeneration.

\subsection{Adipose-Derived Mesenchymal Stem Cell}

Fibroblast-like cells originated from processed lipoaspirate were reported to be expanded cultivated easily, expanded efficiently in vitro. These cells also exhibited adipogenic, osteogenic, chondrogenic, and myogenic differentiation potential when cultured in a medium containing lineage-specific differentiative factors (Zuk et al., 2001). It was reported that the number of stem cells per milliliter of lipoaspirate is about 8 -fold higher than that of the bone marrow. $2 \%$ of nucleated cells are stem cells in lipoaspirate, while only $0.001-0.004 \%$ of them are stem cells in the bone marrow (Strem et al., 2005). Debnath's research revealed that genetic stability of the exponentially growing human ADSCs was maintained without any clonal alterations until passage 5 (Debnath and Chelluri, 2019). By flow cytometry screening, these cells were found expressed CD29, CD44, CD71, CD90, CD105/ $\mathrm{SH} 2$, and $\mathrm{SH} 3$, and absent for CD31, CD34, and CD45 (Zuk et al., 2002). Migration of these cells was confirmed in rabbit models, in which ADSCs were labeled with superparamagnetic iron oxide (SPIO) and were defected in the defect of meniscus (Qi et al., 2016). Compared with the control group, both the gross and histological findings suggested that allogenic ADSC transplantation facilitated the repair of the defected area (Toratani et al., 2017a). These research works demonstrated that ADSCs could effectively migrate to the meniscal defect zone and play an important role in meniscus repair.

\subsection{Cartilage-Derived Chondrogenic Progenitor Cell}

Several studies (Dowthwaite et al., 2004; Hiraoka et al., 2006) reported a chondrocyte subpopulation with progenitor-like characteristics. Among these cells, Notch-1 played a vital role in the process of colony-forming and multipotential differentiation. It has been reported that molecular markers, such as CD29, CD49, CD90, CD44, CD151, and CD166, have been detected in CPCs (Grogan et al., 2007; Candela et al. 2014), and the frequency of cells with molecular marker $\mathrm{CD} 105+$ and $\mathrm{CD} 106+$ was also increased in OA cartilage, while it was decreased in normal human cartilage (Alsalameh et al., 2004). Additionally, higher chondrogenic gene expression of chondrogenic genes was found in CPCs than in BMSCs, suggesting that these cells have a natural advantage in inducing chondrogenesis (Xue et al., 2015). Currently, most studies in the application of CPCs have focused on cartilage regeneration, and few concentrate on meniscus repair. According to Jayasuriya et al. (Jayasuriya et al., 2019), different single cell lines were successfully generated by CPCs, which confirmed the function of CPCs in mediating the rebinding and remodeling of torn meniscal tissues. The well-reintegrated torn meniscus explant demonstrated their proliferative and reparative capacity. The study also shows that these cells were better than BMSCs at preventing terminal differentiation and hypertrophy (Buma et al., 2004). Although the healing potential of CPCs and their superiority have been reported, 
more detailed research is still needed to verify their efficacy in meniscal regeneration.

\subsection{Meniscus-Derived Mesenchymal Stem Cell}

Unlike the MSCs previously mentioned, this type of stem cell has only been discovered and reported in recent years. The MMSC was used for intra-articular injection to treat meniscal tears in the past few years (Shen et al., 2013; Shen et al., 2014). The meniscus tissues were collected, digested, and cultured until a colony was formed in vitro. The authors found these cells with several markers, including CD44, CD90, CD106 and CD105.whereas were negative for CD45 and CD34. (Gamer et al., 2017). What is more, these cells showed better colony-forming capacity than BMSCs and SMSCs, which could be a unique characteristic and superiority of MMSCs for meniscus regeneration. Single-cell RNA sequencing (sc-RNA seq) has been proven to be a powerful technique in investigating the characteristics and the intra-relationship of cell subtypes from certain tissue. By using scRNA seq, Sun et al. (Sun et al., 2020) identified seven cell clusters in the healthy human meniscus, among which endothelial cells (EC) and fibrochondrocyte progenitors (FCP) might be meniscus progenitors by the following pseudotime analysis. This was further confirmed by their expression of MSC marker MCAM (CD146) as well as colony-forming and multidifferentiation capacity in vitro. However, Ding (Ding and Huang, 2015) found that colonies formed by MMSCs were fewer in number and smaller in size than those formed by BMSCs. They also reported that stem cells isolated from rabbit meniscus share similar properties with BMSCs, for no significant differences were found in gene markers and immunostaining results. Most of MMSCs were originated from "Red Zone," the vascular region with good healing potential (Seol et al., 2017). In addition, a larger number of cells expressing CD34 were detected in the peripheral region than inner zone by immunohistochemical staining and flow cytometry (Osawa et al., 2013). Therefore, the authors speculated that the higher multilineage differentiation potential should be attributed to CD34 expression. These findings may help to explain the better histological healing in the peripheral region. Besides, it has been pointed out that whether the repair process occurred spontaneously was uncertain, and growth factors and chemotactic agents might play an important role in MMSCs' migration and differentiation (Seol et al., 2017). For this reason, we assume that exogenous bioactive substances might be conductive to the homing of endogenous MMSCs after injury.

\subsection{MSCs and Meniscus Cell Coculture}

It was reported that coculturing with differentiated cells could direct MSCs' differentiation (Tan et al., 2010). Matthies et al. (Matthies et al., 2013) found that when human BMSCs were cocultured with MCs, the formation of ECM was significantly enhanced ex vivo. According to Kremer et al. (Kremer et al., 2017), the products of coculturing equine BMSCs and MCs were much better than those that under the monoculture condition, and similar to native meniscus with respect to phenotype and composition. It was reported that the 50:50 (BMSC:MC) generated maximal GAG retention and showed optimal mechanical performance (McCorry et al., 2016). But Cui reported that the 25\%: $75 \%$ ratio leads to the highest level of chondrogenic production and lowest hypertrophic gene expression (Cui et al., 2012). In another study (Xie et al., 2018), the coculture system of SMSCs/MCs at the ratio of 3:1 showed higher proliferation and more sGAG secretion than the monoculture did. Compared to SMSCs seeded on the construct separately, coculture with MCs yielded a greater cell survival rate and higher expression of chondrogenic markers (Tan et al., 2010). The effect of ADSCs cocultured with primary human MCs was also explored in a 3D porous scaffold (Weiss et al., 2017), and the mRNA expression level of ACAN in the coculture group was much higher than that in the ADSC group or MC group.

To sum up, MSCs from various tissues showed positive results regarding the enhancement of meniscal repair under $2 \mathrm{D}$ or $3 \mathrm{D}$ culture, in vitro or in vivo. BMSCs were the most thoroughly studied cell types in meniscal regenerative researches, followed by SMSCs and ADSCs; relatively fewer studies have been counted on CPCs and MMSCs. Various studies have confirmed their effect in promoting meniscal healing. The limited quantity and tendency to hypertrophy might be the primary obstacles. Coculture could reduce hypertrophy and promote the directed differentiation into fibrochondrocytes, which might provide a valid approach to address the drawbacks of a limited number of MCs and its tendency to hypertrophy during differentiation of MSCs. However, no consensus has been reached on the optimal ratio for co-cultivation. In general, MSCs from different sources share some similarities, while they also maintain their own unique characteristics. For example, SMSCs held superiority in colony formation and anti-hypertrophy, ADSCs had the advantage in cell quantity, and CPCs in cartilage-directed differentiation. These characteristics could provide guidance for researchers to choose which seeded cells to be used in meniscal repair studies. Taking their verified regenerative capabilities into consideration, it is reasonable for us to believe that the source of MSCs would not be the most limiting factor affecting meniscus repair. We should pay more attention on how to exert their regenerative properties and maintain effective directional differentiation. The question seems to be the applicability of MSCs for meniscus regeneration, rather than their availability in researches.

\section{APPROACHES TO MSC UTILIZATION}

There are roughly two ways to deliver MSCs into the impaired site: one is the direct injection of a suspension into the knee (onestep), and the other is first to preculture and expansion in vitro and then implant into the defect zone (two-step) (Anderson et al., 2014). Scaffold-free strategies, such as "high-density" cell aggregation or fibrin-based solutions, promoted histological meniscus healing in animal models, which are also promising repair techniques for meniscal tears (Toratani et al., 2017b; Marom et al., 2021). However, in large meniscal defects, MSCs usually exert only limited biological response in the process of meniscal regeneration for the lack of attachment site. Therefore, 


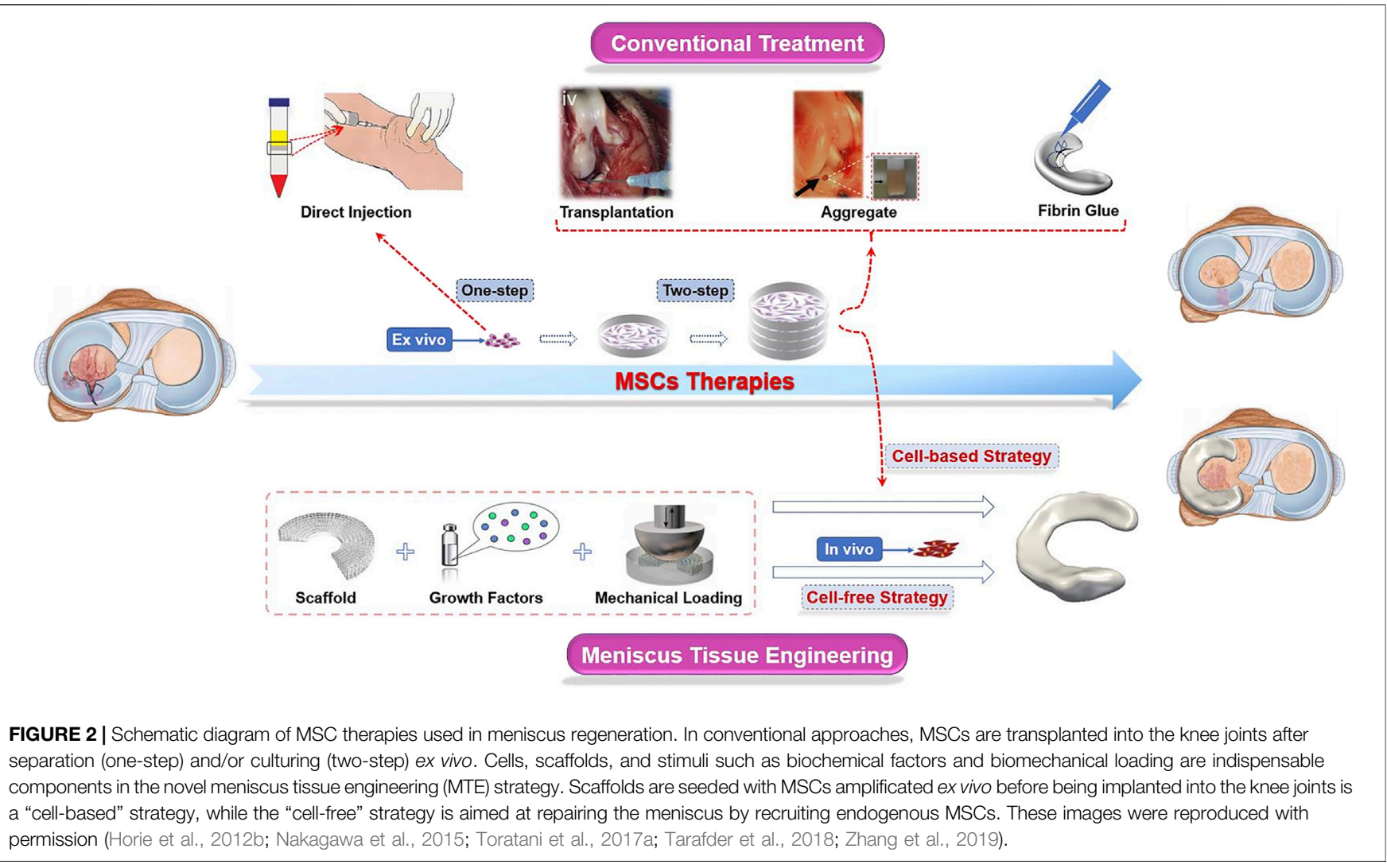

carriers and scaffolds are commonly used in the damaged site to provide a platform for cell attachment, proliferation, and differentiation (Tanaka et al., 2010). The technique of partially or totally replacement of damaged menisci with artificial engineered constructs is known as meniscus tissue engineering (MTE), a novel approach different from traditional MSC treatments (Figure 2). Generally, the one-step cell-based method is usually used to treat meniscus injuries by isolating and transplanting MSCs. The two-step approach requires preculture and expansion in vitro. The expanded cells from a variety of tissues could be transplanted into the damaged meniscus areas alone or carried by biomaterials (Table 1).

In this section, we summarized the main approaches of MSCs for meniscal repair. For the sake of description, we have artificially defined them as conventional strategies and novel approaches, and the latter mainly includes MTE (based on scaffold), while the rest (cell aggregate or fibrin-based solutions) are included in the former. In particular, direct injection or delivery via various scaffold media/materials are commonly used avenues to directional implantation for cellbased techniques. The cell-free strategy is based on the recruitment of endogenous MSCs.

\subsection{Conventional Strategies}

\subsubsection{Intra-Articular MSC Injection}

The intra-articular injection was a commonly used method to treat meniscal lesions in early research works (Abdel-Hamid et al., 2005; Horie et al., 2012a; Hatsushika et al., 2014). $2 \mathrm{ml}$ autologous bone marrow cells were separated by centrifugation and injected into the dog articular cavity (Abdel-Hamid et al., 2005). MSCs were also injected into knee joints by cell counting $\left(2-6 \times 10^{6}\right.$ or $5 \times 10^{6}$ in rat models (Horie et al., 2009; Horie et al., 2012a; Shen et al., 2014) and $5 \times 10^{7}$ in pig models (Hatsushika et al., 2014)) rather than by volume. These cells were injected into the knees immediately after the skin incision closed (one injection only) or 2 weeks later (three times injection at 2-week intervals). The angiogenesis, chondrogenesis, immune cell infiltration, and collagen deposition of repaired menisci in the injected joints were much higher than those in the non-injected object. Needles were often used to deliver the cells directly transplanted to the targeted damaged sites (Horie et al., 2012b; Nakagawa et al., 2015). The knees were kept still for a few minutes after solution injection, then the sutures were tightened, and the capsule and skin were closed. Miguel et al. (Ruiz-Ibán et al., 2011) also reported meniscal healing by using ADSCs in the same way. These cells were suspended in the gel phase after in vitro culture and then instilled into the lesion followed by tightening the knots. The results manifested that the healing of the avascular meniscus was improved, especially in the acute phase. The expanded MMSCs between P1 P3 were injected into rat meniscectomy models. The results verified the contribution on meniscal repair for the more neo-tissue formation and ECM deposition at an early stage after injection (Shen et al., 2014). Another method of cell transplantation is the aggregation of MSCs. The hanging drop culture method was used in cultivating SMSCs, which contained $2.5 \times 10^{5}$ MSCs for each after culturing 3 days, and then several 
TABLE 1 | Classification based on approaches of MSC therapies.

\begin{tabular}{|c|c|c|c|c|c|}
\hline Approaches & Cell & $\begin{array}{c}\text { Cell } \\
\text { implant }\end{array}$ & $\begin{array}{l}\text { Dosage of } \\
\text { cells }\end{array}$ & Outcome & Animal model \\
\hline \multirow[t]{3}{*}{ Intra-articular injection } & BMSC & $\begin{array}{l}\text { One-step, } \\
\text { once }\end{array}$ & $2 \mathrm{ml} / \mathrm{knee}$ & Improved meniscal wound healing & Dog \\
\hline & & $\begin{array}{l}\text { Two-step, } \\
\text { once }\end{array}$ & $5 \times 10^{6}$ cells/knee & $\begin{array}{l}\text { Adhered to the lesion, differentiated into meniscal cells } \\
\text { directly, and promoted meniscal regeneration }\end{array}$ & Rat \\
\hline & SMSC & $\begin{array}{l}\text { Two-step, } \\
\text { repetitive }\end{array}$ & $5 \times 10^{7}$ cells/knee & $\begin{array}{l}\text { Defect filled with synovial tissue. Articular cartilage and } \\
\text { subchondral bone were effectively preserved }\end{array}$ & Pig \\
\hline \multirow[t]{2}{*}{$\begin{array}{l}\text { Transplant to meniscal } \\
\text { lesion sites }\end{array}$} & ADSC & $\begin{array}{l}\text { Two-step, } \\
\text { once }\end{array}$ & $1 \times 10^{5}$ cells $/$ model & $\begin{array}{l}\text { Meniscal healing was histologically increased when } \\
\text { suture immediately }\end{array}$ & Rabbit \\
\hline & SMSC & $\begin{array}{l}\text { Two-step, } \\
\text { once }\end{array}$ & $2 \times 10^{7}$ cells $/$ model & $\begin{array}{l}\text { Adhered to injury sites, differentiated into } \\
\text { fibrochondrocytes, and enhanced meniscal } \\
\text { regeneration and tensile strength }\end{array}$ & $\begin{array}{l}\text { Rabbit, } \\
\text { microminipig }\end{array}$ \\
\hline \multirow[t]{2}{*}{ Aggregate } & ADSC & $\begin{array}{l}\text { Two-step, } \\
\text { once }\end{array}$ & 1 cylindrical plug/model & $\begin{array}{l}\text { Adhered to the defect and promoted histological } \\
\text { meniscus healing }\end{array}$ & Rabbit \\
\hline & SMSC & $\begin{array}{l}\text { Two-step, } \\
\text { once }\end{array}$ & $\begin{array}{l}500 \times 10^{6} \text { cells/aggregate, } 1-50 \\
\text { per knee }\end{array}$ & $\begin{array}{l}\text { Promoted meniscus regeneration and delayed } \\
\text { progression of degeneration of articular cartilage }\end{array}$ & $\begin{array}{l}\text { Primates, } \\
\text { rat, pig }\end{array}$ \\
\hline Fibrin glue & BMSCs & $\begin{array}{l}\text { Two-step, } \\
\text { once }\end{array}$ & $1 \times 10^{6}$ cells $/$ model & $\begin{array}{l}\text { MSCs in fibrin glue significantly produced an abundant } \\
\text { ECM, increased total bonding, and enhanced meniscal } \\
\text { healing, but the mechanical properties of the repair } \\
\text { tissue decreased }\end{array}$ & $\begin{array}{l}\text { Rabbit, rat, pig, } \\
\text { horse }\end{array}$ \\
\hline \multirow[t]{3}{*}{$\begin{array}{l}\text { Tissue-derived } \\
\text { materials }\end{array}$} & None & - & SIS scaffold without cells & $\begin{array}{l}\text { Be conducive for cellular repopulation with host meniscal } \\
\text { characteristics and be capable of supporting the } \\
\text { complete healing of a large defect. But cartilage } \\
\text { degeneration happened }\end{array}$ & $\begin{array}{l}\text { Rabbit, } \\
\text { goat, dog }\end{array}$ \\
\hline & BMSC & $\begin{array}{l}\text { Two-step, } \\
\text { once }\end{array}$ & $\begin{array}{l}\text { Unspecified silk fibroin scaffolds } \\
\text { incubated in BMSC-rich well }\end{array}$ & $\begin{array}{l}\text { Showed compatibility and feasibility of structure, and } \\
\text { function in meniscal repair }\end{array}$ & Rabbit \\
\hline & $\begin{array}{l}\text { Coculture (MC } \\
+ \text { SMSC) }\end{array}$ & $\begin{array}{l}\text { Two-step, } \\
\text { once }\end{array}$ & $0.9 \times 10^{6}$ cells/construct & $\begin{array}{l}\text { Enhanced cell survival and differentiation into } \\
\text { chondrogenic phenotypes }\end{array}$ & Pig \\
\hline \multirow{4}{*}{$\begin{array}{l}\text { ECM component- } \\
\text { derived bioscaffolds }\end{array}$} & None & - & Acellular test & Improved the joint contact mechanics & In vitro \\
\hline & MC & - & Unspecified & Be capable of MC attraction and matrix formation & In vitro \\
\hline & SMSCs & $\begin{array}{l}\text { Two-step, } \\
\text { once }\end{array}$ & $4.4 \times 10^{5} \mathrm{SMSCs} / \mathrm{model}$ & $\begin{array}{l}\text { Effectively promoted cellular infiltration, proliferation, } \\
\text { survival, migration, and proliferation }\end{array}$ & Dog \\
\hline & MMSC & $\begin{array}{l}\text { Two-step, } \\
\text { once }\end{array}$ & $1-1.3 \times 10^{6} \mathrm{cells} / \mathrm{model}$ & $\begin{array}{l}\text { Increased cell proliferation and chondrogenic gene } \\
\text { expression, and improved mechanical properties }\end{array}$ & Rabbit, dog \\
\hline \multirow[t]{3}{*}{$\begin{array}{l}\text { Synthetic polymeric } \\
\text { scaffolds }\end{array}$} & None & - & $\begin{array}{l}\text { PCL and HC (or PLLA and PGA) } \\
\text { hybrid scaffolds without cell } \\
\text { seeding }\end{array}$ & $\begin{array}{l}\text { Histological investigation revealed tissue formation, } \\
\text { cellular infiltration, and vascularization. Possessed } \\
\text { biological and biomechanical functions for meniscal } \\
\text { regeneration }\end{array}$ & Rabbit, sheep \\
\hline & $\mathrm{MC}$ & $\begin{array}{l}\text { Two-step, } \\
\text { once }\end{array}$ & $\begin{array}{l}\sim 10^{6} \text { cells } / \mathrm{ml} \text { seeded onto } \\
\text { PLDLA/PCL-T scaffolds }\end{array}$ & $\begin{array}{l}\text { Increased the formation of fibrocartilaginous tissue, PEG } \\
\text { increased Col II mRNA expression, and higher GAG } \\
\text { production }\end{array}$ & Rabbit, sheep \\
\hline & BMSC & $\begin{array}{l}\text { Two-step, } \\
\text { once }\end{array}$ & $4-5 \times 10^{6}$ cells/scaffold & $\begin{array}{l}\text { Increased well-integrated fibrocartilaginous tissue } \\
\text { regeneration and mechanical strength }\end{array}$ & Rabbit \\
\hline \multirow[t]{4}{*}{ Hydrogels } & None & - & $\begin{array}{l}\text { Artificial hydrogel without cell } \\
\text { seeding }\end{array}$ & $\begin{array}{l}\text { Improved the contact mechanics. Promising results at } \\
\text { early times, but joint degeneration and implant failure } \\
1 \text { year later }\end{array}$ & Sheep, ovine \\
\hline & $\mathrm{MC}$ & $\begin{array}{l}\text { Two-step, } \\
\text { once }\end{array}$ & $\begin{array}{l}5 \times 10^{7} \text { cells } / \mathrm{ml} \text { gel, or } 2 \times 10^{5} \text { cells/ } \\
\text { scaffold }\end{array}$ & $\begin{array}{l}\text { Had good compatibility with MCs, growth factor } \\
\text { increased the mechanical and biochemical properties. } \\
\text { Promoted cell proliferation and fibrocartilaginous ECM } \\
\text { production }\end{array}$ & In vitro \\
\hline & BMSC & $\begin{array}{l}\text { Two-step, } \\
\text { once }\end{array}$ & $3 \times 10^{7} \mathrm{cells} / \mathrm{ml} \mathrm{gel}$ & $\begin{array}{l}\text { MSCs in meniscus ECM hydrogel enhanced tissue } \\
\text { regeneration and protection from joint deterioration }\end{array}$ & Rat \\
\hline & $\begin{array}{l}\text { Coculture (MC } \\
+\mathrm{BMSC})\end{array}$ & $\begin{array}{l}\text { Two-step, } \\
\text { once }\end{array}$ & $0.5 \times 10^{5}$ cells $/ \mathrm{ml} \mathrm{gel}$ & Increased meniscus-like ECM production & Equine \\
\hline
\end{tabular}

aggregates were placed in the meniscus (Kondo et al., 2017). ADSCs were cultured and aggregated into a spheroid structure and transplanted into the meniscal defect (Toratani et al., 2017a). These results showed that transplantation of aggregates could promote meniscus regeneration and delay the progression of degeneration of articular cartilage. What is more, it has been reported that transplantation of aggregates of SMSCs regenerated the meniscus more effectively than intra-articular injection with the same cell number used (Katagiri et al., 2013). In general, studies in direct injection of MSCs were still relatively limited, and there was no clear definition of the optimal number of cells to achieve the satisfying therapeutic effect. We proposed that the animal species may differ in their need of cell number; animals with larger joints generally require more cells. Although the 

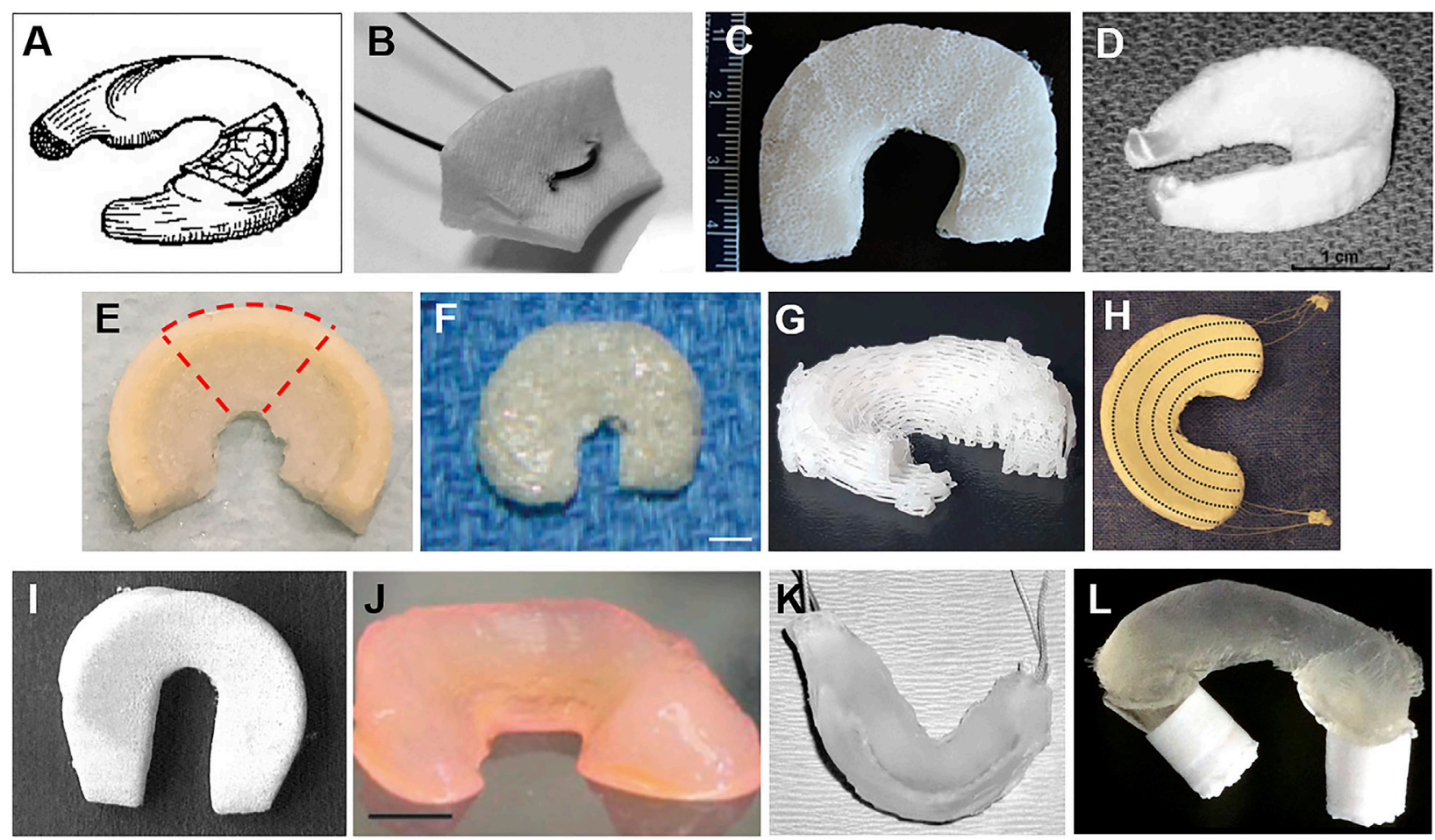

FIGURE 3 | Different kinds of meniscus scaffolds. (A) The SIS meniscal implant (Cook et al., 2006) was used in a dog model. (B) The collagen meniscal implant (Gwinner et al., 2017) was sectioned radially, creating specimens of $15 \mathrm{~mm}$ width to measure its biomechanical properties. (C) Multiporous silk scaffold composing of three individual layers with different pore sizes and orientations in each layer (Mandal et al., 2011). (D) Fiber-weaved meniscus scaffold from bovine dermal collagen reinforced by a network of degradable tyrosine-derived polymer fibers (Balint et al., 2012). (E) The 3D-printed polymer network infusing with collagen-hyaluronic acid (Ghodbane et al., 2019b). (F) Meniscus-shaped PGA mesh scaffold of a rabbit model (scale bar: 4 mm) (Kang et al., 2006). (G) A 3D-printed PCL meniscus scaffolds with a biomimetic fiber architecture (Szojka et al., 2017). (H) A porous scaffold composited of PCL and HYAFF ${ }^{\oplus}$ and augmented with circumferential PLA fibers (Chiari et al., 2006). (I) A meniscus scaffold fabricated by PCLPU for a dog model (Welsing et al., 2008). (J) Anatomically shaped alginate meniscus (scale bar: 5 mm) (Puetzer et al., 2013). (K) Hydrogel meniscal construct with sutures woven through the anterior and posterior horn used in a sheep model (Kelly et al., 2007). (L) Thermoplastic elastomer (TPE) hydrogel with tabs swollen into PLA cylinders (Fischenich et al., 2018).

aggregate contained more cells for its ex vivo culture, it does not seem to be a widespread method in meniscus repair studies.

One-step cell implantation was not widely used in the studies because of limited cell numbers. In fact, more research works had adopted the two-step method. The MSCs are usually implanted into the joints by cell suspension or aggregation. In order to enable MSCs to perform their biological function in a specific region, certain vehicles were usually used for transportation, such as liquid fibrin glue and specific shaped scaffold. The former helps MSCs gather and stick to the damaged area, and the latter provides a platform for cell attachment, and its shape serves as a template reference for the finally formed tissue.

\subsubsection{Fibrin Glue}

Fibrin glue loaded with BMSCs has been reported to treat meniscal defects in rabbits. Healing of meniscus tissues had been observed 3 weeks after the operation, which showed better short-term results than those treated with acellular fibrin glue (Ishimura et al., 2000). The results were different from those reported in 1996, which indicated that the combination of autologous bone marrow cells and exogeneous fibrin clots would not enhance the meniscal healing (Port et al., 1996). The disparate results from these studies might be on account of the advancement in extraction and utilization of MSCs, and an improved property of fibrin glue. In subsequent studies, transplanted green fluorescent protein (GFP) cells carried by fibrin glue were detected in rats until 8 weeks. This study clearly demonstrated that allogenic MSCs embedded in fibrin glue could survive and proliferate in the meniscal defect in the avascular status, and promote the meniscal healing process (Izuta et al., 2005). BMSCs could sustain abilities of survival and differentiation when integrated with fibrin glue (Dutton et al., 2010), and the combined constructs implanted subcutaneously in nude mice showed significantly increased vascularization and tissue bonding (Ferris et al., 2012). What is more, a novel approach to treat avascular meniscus tears without exogenous stem cells has been reported (Tarafder et al., 2018). Endogenous SMSCs could be recruited, and fibrous matrix could be generated with the induction of growth factors loaded in fibrin glue.

\subsection{Novel Approaches}

Fibrin glue enhances the reconnection level in the torn meniscus, and the MSCs strengthen the neo-tissue formation and ECM deposition. For meniscus defect, cells lose the substrate to adhere and further differentiate, leading to less effective tissue regeneration. 
Artificial engineered scaffolds might ideally compensate for this. As an integral part of tissue engineering, scaffolds could partially or completely replace the impaired or degenerated menisci. The goal of MTE is to finally generate constructs that mimic native gradient menisci. Scaffolds could be generally categorized into four classes based on their compositions (Zhang et al., 2015): tissue-derived materials, ECM component-derived bio scaffolds, synthetic porous polymeric scaffolds, and hydrogels (Figure 3).

\subsubsection{Tissue-Derived Materials}

Small intestinal submucosa (SIS), an early published material type, was commonly used in soft-tissue repair after the removal of all cellular and nuclear materials. Its mechanical and biological properties would be beneficial to cell infiltration, matrix formation, and neo-tissue remodeling after scaffold biodegradation (Gastel et al., 2001; Bradley et al., 2007). It was reported (Tan et al., 2010) that SIS scaffolds consisted of $80-90 \%$ collagen with oriented fibers, containing GAGs and soluble factors. SIS scaffold implantation resulted in more meniscus-like tissue production than meniscectomy, and seeding cells on SIS seemed a promising approach to meniscus repair (Cook et al., 2006). Though this material has many advantages, like high bioactivity, it has not gained enough attention at present due to several drawbacks: limited sources and insufficient mechanical strength. Silk fibroin is another material derived from tissue with outstanding biocompatibility and mechanical properties. Silk fibroin solution (Mandal et al., 2011) was prepared from Bombyx mori silkworm cocoons and then further fabricated into a scaffold. The cell-seeded silk constructs confirmed the deposition of sGAG and Col I and II by histological and immunohistochemical assessments. The histocompatibility and feasibility of structure and function, as well as controlled degradability, were also confirmed by various studies (Wang et al., 2008; Ying et al., 2018). Combined silk scaffolds (Liu et al., 2015) and composited scaffolds (Shi et al., 2017) were successfully explored and used for tissue regeneration in combination with MSCs, and they were fabricated by forming microporous silk sponges in the knitted silk or designed by integrating silk fibroin with gelatin. These findings demonstrated that the tissue-derived scaffolds have their own advantages, especially in biocompatibility. Nevertheless, few research works focused on this kind of scaffold, probably on account of their limited sources.

\subsubsection{ECM Component-Derived Bio Scaffolds}

ECM plays a vital role in maintaining the biological and biomechanical properties of native menisci. Similar to tissuederived scaffolds, ECM-derived biomaterials are also non-cellular tissues that provide platforms for cell attachment and regulate cell differentiation, matrix generation, as well as tissue morphogenesis and homeostasis (FA and Cook, 2017). Theoretically, the tissuederived ECM biomaterials can serve as a substrate that is close to the native state and contribute to cell attachment and proliferation. Collagen is the dominant protein in the ECM, and collagen meniscus implant (CMI) is the only Food and Drug Administration (FDA)approved partial meniscus substitution that serves as a biodegradable template for cell ingrowth (Gwinner et al., 2017). Hyaluronan could play an important role in collagen remodeling after meniscus injury (Sonoda et al., 2000). Derived from natural sources, collagen-derived scaffolds might possess favorable biocompatibility and biodegradability for cell seeding (Kremer et al., 2017). Collagen and hyaluronic acid composited scaffolds replicate the key structure and load-distribution properties of the native meniscus, which could approximately restore the joints' normal axial compression and circumferential tensile stress (Ghodbane et al., 2019a). Histological evidence, ECM deposition, and immunohistochemical staining born out that scaffolds were effectively involved in meniscus tissue reconstruction (Merriam et al., 2015). ECM-derived components are essential subsets of biomimetic scaffolds, which hold excellent properties for cell attachment and proliferation, as well as biofunction restoration. It is worth noticing that the scaffolds were reinforced by polymer fiber fabricated by the $3 \mathrm{D}$ technique in recent research works. The voids of the 3D-printed polymer are beneficial for the infiltrating of MSCs, and the composited biomaterials with different mechanical properties provide substrates for cellar anisotropic differentiation.

\subsubsection{Synthetic Porous Polymeric Scaffolds}

Multiple sources of materials were reported in the research works of synthetic bioscaffolds up to now, such as poly (L-lactide) (PLLA), poly (p-dioxanone) (PPD), polyglycolide (PGA), poly (lactide-coglycolide) (PLGA), poly ( $\varepsilon$-caprolactone) (PCL), and polyurea-poly (L-lactide) (PU-PLLA) (Koller et al., 2012; Esposito et al., 2013; Rongen et al., 2014; Murakami et al., 2017; Shimomura et al., 2017; Zhang et al., 2017; Koch et al., 2018). Electrospinning techniques and 3D printing technology are commonly used methods to obtain patient-specific constructs, aiming at narrowing the morphological differences between the artificial material and native tissue (LópezCalzada et al., 2016; Szojka et al., 2017). The porous structure provided avenues for cell infiltration and ECM deposition, and facilitated the neo-tissue formation. Biomimetic porous polymeric scaffolds fabricated by the 3D printing technology have been receiving growing attention in MTE research in recent years (Williams et al., 2018). Different origins of materials, construct architectures, and manufacturing methods have been developed to fabricate scaffolds (Szojka et al., 2017). In general, the circumferential and internal fiber orientation was designed to mimic the skeleton of the native menisci. Mechanical stimulation and biochemical factors were selectively added to the material or the construct to enable seed cells to differentiate into the targeted mature type and construct anatomically zone-specific menisci (Zhang et al., 2015). Both cellular and acellular synthetic scaffolds were implanted into the meniscal defects. Encouragingly, both of them had finally generated anisotropic menisci, making a great progress in MTE (Lee et al., 2014). Although there are still some disadvantages like lack of bioactivity and hydrophilic properties, these materials still play an important role and hold new promising prospects in meniscal regeneration.

\subsubsection{Hydrogel Scaffolds}

Hydrogels, also known as hydrophilic gels or sometimes colloidal gels, are polymer networks based on cross-linked hydrophilic polymers with water as the dispersion medium (Ahmed, 2015). This material could be made from a wide range of natural and synthetic polymers, and classified into chemical and physical categories according to their cross-linking mechanism (Zhu and 
Marchant, 2011). The chemical cross-linked structures are formed by covalent or ionic bonds with closely aligned and permanent junctions, while the other is weakly interacted by physical twining or connected by hydrogen bonds (Slaughter et al., 2009). Natural polymer-derived hydrogels, such as fibrin, alginate, gelatin, and collagen, are liable to mimic the native menisci with outstanding biocompatibility and biodegradability, but the weak mechanical properties make this material expose to the risk of breakage, while the lack of adequate biological activities is the biggest drawback for synthetic hydrogel (Brandl et al., 2007; Kelly et al., 2007; Puetzer et al., 2013). The synthetic and natural hybrid hydrogels (i.e., the combination of these two polymers) have been employed to control the scaffolds' matrix architecture, which could simultaneously affect the cellular response (Anjum et al., 2016).

Hydrogel scaffold implantation could partially restore contact area and pressure distribution of the knee, especially in the lateral compartment (Fischenich et al., 2018). Compared with 3D PCL scaffolds with stronger mechanics, the hydrogel scaffolds were more conducive to the production of meniscus ECM (Bahcecioglu et al., 2019b). Moreover, the sources of hydrogel might exert influences on the heterogeneous differentiation of the MSCs. Recently, a PCL/ hydrogel composite biomaterial has been explored (Bahcecioglu et al., 2019a). Bahcecioglu G et al. impregnated agarose (Ag) and methacrylated gelatin hydrogels into PCL scaffolds in the inner and outer regions, respectively. The constructs generated cartilagelike tissue at the inner zone and fibrocartilage-like tissue at the outer zone, thus showing a new promising approach to engineer an anisotropic substitution. Hydrogels' networks can also provide platforms for the incorporation of bioactive molecules or MSCs according to the need of the research (Koh et al., 2017; Yuan et al., 2017). This controlled delivery system could be designed because the physicochemical properties of the hydrogels are sensitive to $\mathrm{pH}$, temperature, and chemical reaction. The adjustable release of these substances in time and space might affect the cellular differentiation and tissue remodeling. Overall, hydrogels could be used as not only carriers but also scaffolds. However, what should be borne in mind is that it is necessary to balance the relationship between mechanical strength and biological properties. To solve this problem, the combination of materials from different sources might provide a feasible approach. Several injectable hydrogels were used as a carrier to deliver MSCs, most of which are based on a natural hydrogel and reinforced with synthetic materials (Zhong et al., 2020; An et al., 2021).

\section{CONCLUSION AND PROSPECT}

Taken together, current research works are more focused on scaffolds seeded with MSCs. MTE is an ever-growing research field with emerging strategies that aim to restore and improve meniscal function. Various engineered scaffolds have been successfully fabricated with bionics of morphology and structure at present, which has made a great progress in meniscus regeneration. Although the cell-scaffold composite shows excellent healing potential, the cell-based two-step strategy has its drawbacks including cell contamination in the process of cell expansion in vitro. The cell-free method with one-step scaffold implantation has been getting more and more attention. This technique effectively avoids the complications in the procedure of cell culturing in vitro. This technique might provide greater expectation for the research works of meniscus regeneration in the future if enough MSCs could be collected and differentiated into fibrochondrocytes. How to get these materials more involved in the biological reaction play their regulatory role in cell-directed differentiation and ultimately form a substitute with heterogeneity in composition, and biomechanical properties need further investigation.

Meniscus lesion is a common knee injury and usually results in degenerative changes of the joints. It is hard to repair spontaneously once injured or defected, especially for the white region, which refers to the region with poor vascular supply and low cellularity. MSCs are widely used in meniscus regeneration because of their abundant sources, availability, and outstanding differentiation capability. Conventional treatments with MSCs include direct application, articular injection, and transplantation of aggregates. MTE is a burgeoning approach for meniscus regeneration, which is composed of several elements such as seeding cells and various scaffolds. MSCs are the basis for matrix formation, while scaffolds are essentially engineered replacements that provide mechanical support, promote cell adhesion and growth, and guide three-dimensional tissue formation. Despite that MTE has made significant progress in recent years, research on the engineered meniscus regeneration using MSC is still in the laboratory or animal exploration stage. How to realize the clinical transformation of regenerative medicine and bring the benefits to more patients with meniscus injury is the ultimate goal of our research. Accordingly, more valuable research works are needed to explore anisotropic meniscus substitution in line with clinical demand.

\section{DATA AVAILABILITY STATEMENT}

The original contributions presented in the study are included in the article/Supplementary Material, and further inquiries can be directed to the corresponding author.

\section{AUTHOR CONTRIBUTIONS}

Z-ZZ and Y-FZ conceived and designed the study. Y-FZ participated in the study design and mainly performed the manuscript preparation. DZ helped to draft the manuscript. W-TY and KL contributed to the study design and review of the manuscript. All authors read and approved the final manuscript.

\section{FUNDING}

This study was financially supported by grants from the National Outstanding Youth Science Fund Project of National Natural Science Foundation of China (82022046), the Natural Science Foundation of Guangdong Province for Distinguished Young Scholars (2020B1515020014) and the Faculty Development Grants of Xiangyang No.1 People's Hospital Affiliated to Hubei University of Medicine (XYY2021D06). 


\section{REFERENCES}

Abdel-Hamid, M., Hussein, M. R., F. Ahmad, A., and Elgezawi, E. M. (2005). Enhancement of the Repair of Meniscal Wounds in the Red-white Zone (Middle Third) by the Injection of Bone Marrow Cells in Canine Animal Model. Int. J. Exp. Pathol. 86 (2), 117-123. doi:10.1111/j.0959-9673.2005. 00420.x

Ahmed, E. M. (2015). Hydrogel: Preparation, Characterization, and Applications: A Review. J. Adv. Res. 6 (2), 105-121. doi:10.1016/j.jare.2013.07.006

Alsalameh, S., Amin, R., Gemba, T., and Lotz, M. (2004). Identification of Mesenchymal Progenitor Cells in normal and Osteoarthritic Human Articular Cartilage. Arthritis Rheum. 50 (5), 1522-1532. doi:10.1002/art.20269

Alvarez-Viejo, M., Menendez-Menendez, Y., Blanco-Gelaz, M. A., FerreroGutierrez, A., Fernandez-Rodriguez, M. A., Gala, J., et al. (2013). Quantifying Mesenchymal Stem Cells in the Mononuclear Cell Fraction of Bone Marrow Samples Obtained for Cell Therapy. Transplant. Proc. 45 (1), 434-439. doi:10.1016/j.transproceed.2012.05.091

An, Y. H., Kim, J. A., Yim, H. G., Han, W. J., Park, Y. B., Jin Park, H., et al. (2021). Meniscus Regeneration with Injectable Pluronic/PMMA-Reinforced Fibrin Hydrogels in a Rabbit Segmental Meniscectomy Model. J. Tissue Eng. 12, 20417314211050141. doi:10.1177/20417314211050141

Anderson, J. A., Little, D., Toth, A. P., Moorman, C. T., Tucker, B. S., Ciccotti, M. G., et al. (2014). Stem Cell Therapies for Knee Cartilage Repair. Am. J. Sports Med. 42 (9), 2253-2261. doi:10.1177/0363546513508744

Anjum, F., Lienemann, P. S., Metzger, S., Biernaskie, J., Kallos, M. S., and Ehrbar, M. (2016). Enzyme Responsive GAG-Based Natural-Synthetic Hybrid Hydrogel for Tunable Growth Factor Delivery and Stem Cell Differentiation. Biomaterials 87, 104-117. doi:10.1016/j.biomaterials.2016.01.050

Bahcecioglu, G., Hasirci, N., Bilgen, B., and Hasirci, V. (2019). A 3D Printed PCL/ hydrogel Construct with Zone-specific Biochemical Composition Mimicking that of the Meniscus. Biofabrication 11 (2), 025002. doi:10.1088/1758-5090/ aaf707

Bahcecioglu, G., Hasirci, N., Bilgen, B., and Hasirci, V. (2019). Hydrogels of Agarose, and Methacrylated Gelatin and Hyaluronic Acid Are More Supportive for In Vitro Meniscus Regeneration Than Three Dimensional Printed Polycaprolactone Scaffolds. Int. J. Biol. Macromolecules 122, 1152-1162. doi:10.1016/j.ijbiomac.2018.09.065

Balint, E., Gatt, C. J., Jr., and Dunn, M. G. (2012). Design and Mechanical Evaluation of a Novel Fiber-Reinforced Scaffold for Meniscus Replacement. J. Biomed. Mater. Res. 100A (1), 195-202. doi:10.1002/jbm.a.33260

Barber-Westin, S. D., and Noyes, F. R. (2014). Clinical Healing Rates of Meniscus Repairs of Tears in the central-third (red-white) Zone. Arthrosc. J. Arthroscopic Relat. Surg. 30 (1), 134-146. doi:10.1016/j.arthro.2013.10.003

Bilgen, B., Jayasuriya, C. T., and Owens, B. D. (2018). Current Concepts in Meniscus Tissue Engineering and Repair. Adv. Healthc. Mater. 7 (11), e1701407. doi:10.1002/adhm.201701407

Bradley, M. P., Fadale, P. D., Hulstyn, M. J., Muirhead, W. R., and Lifrak, J. T. (2007). Porcine Small Intestine Submucosa for Repair of Goat Meniscal Defects. Orthopedics 30 (8), 650-656. doi:10.3928/01477447-20070801-15

Brandl, F., Sommer, F., and Goepferich, A. (2007). Rational Design of Hydrogels for Tissue Engineering: Impact of Physical Factors on Cell Behavior. Biomaterials 28 (2), 134-146. doi:10.1016/j.biomaterials.2006.09.017

Buma, P., Ramrattan, N. N., van Tienen, T. G., and Veth, R. P. H. (2004). Tissue Engineering of the Meniscus. Biomaterials 25 (9), 1523-1532. doi:10.1016/ s0142-9612(03)00499-x

Candela, M. E., Yasuhara, R., Iwamoto, M., and Enomoto-Iwamoto, M. (2014). Resident Mesenchymal Progenitors of Articular Cartilage. Matrix Biol. 39, 44-49. doi:10.1016/j.matbio.2014.08.015

Caplan, A. I., and Dennis, J. E. (2006). Mesenchymal Stem Cells as Trophic Mediators. J. Cel. Biochem. 98 (5), 1076-1084. doi:10.1002/jcb.20886

Chen, Z., Li, W. P., Yang, R., Song, B., Jiang, C., Hou, J. Y., et al. (2018). Meniscal Ramp Lesion Repair Using the FasT-Fix Technique: Evaluating Healing and Patient Outcomes with Second-Look Arthroscopy. J. Knee Surg. 31 (8), 710-715. doi:10.1055/s-0037-1606378

Chiari, C., Koller, U., Dorotka, R., Eder, C., Plasenzotti, R., Lang, S., et al. (2006). A Tissue Engineering Approach to Meniscus Regeneration in a Sheep Model. Osteoarthritis and Cartilage 14 (10), 1056-1065. doi:10.1016/j.joca.2006.04.007
Cook, J. L., Fox, D. B., Malaviya, P., Tomlinson, J. L., Kuroki, K., Cook, C. R., et al. (2006). Long-term Outcome for Large Meniscal Defects Treated with Small Intestinal Submucosa in a Dog Model. Am. J. Sports Med. 34 (1), 32-42. doi:10. $1177 / 0363546505278702$

Cossu, G., Birchall, M., Brown, T., De Coppi, P., Culme-Seymour, E., Gibbon, S., et al. (2018). Lancet Commission: Stem Cells and Regenerative Medicine. The Lancet 391 (10123), 883-910. doi:10.1016/s0140-6736(17)31366-1

Cui, X., Hasegawa, A., Lotz, M., and D'Lima, D. (2012). Structured ThreeDimensional Co-culture of Mesenchymal Stem Cells with Meniscus Cells Promotes Meniscal Phenotype without Hypertrophy. Biotechnol. Bioeng. 109 (9), 2369-2380. doi:10.1002/bit.24495

Dai, T., Pan, Z., and Yin, F. (2021). In Vivo Studies of Mesenchymal Stem Cells in the Treatment of Meniscus Injury. Orthop. Surg. 13, 2185. doi:10.1111/os.13002

Danso, E. K., Oinas, J. M. T., Saarakkala, S., Mikkonen, S., Töyräs, J., and Korhonen, R. K. (2017). Structure-function Relationships of Human Meniscus. J. Mech. Behav. Biomed. Mater. 67, 51-60. doi:10.1016/j.jmbbm. 2016.12.002

Debnath, T., and Chelluri, L. K. (2019). Standardization and Quality Assessment for Clinical Grade Mesenchymal Stem Cells from Human Adipose Tissue. Hematol. Transfus. Cel Ther. 41 (1), 7-16. doi:10.1016/j.htct.2018.05.001

Del Rey, M. J., Faré, R., Usategui, A., Cañete, J. D., Bravo, B., Galindo, M., et al. (2016). CD271+ Stromal Cells Expand in Arthritic Synovium and Exhibit a Proinflammatory Phenotype. Arthritis Res. Ther. 18, 66. doi:10.1186/s13075016-0966-5

Ding, Z., and Huang, H. (2015). Mesenchymal Stem Cells in Rabbit Meniscus and Bone Marrow Exhibit a Similar Feature but a Heterogeneous MultiDifferentiation Potential: Superiority of Meniscus as a Cell Source for Meniscus Repair. BMC Musculoskelet. Disord. 16, 65. doi:10.1186/s12891015-0511-8

Dominici, M., Le Blanc, K., Mueller, I., Slaper-Cortenbach, I., Marini, F. C., Krause, D. S., et al. (2006). Minimal Criteria for Defining Multipotent Mesenchymal Stromal Cells. The International Society for Cellular Therapy Position Statement. Cytotherapy 8 (4), 315-317. doi:10.1080/14653240600855905

Dowthwaite, G. P., Bishop, J. C., Redman, S. N., Khan, I. M., Rooney, P., Evans, D. J. R., et al. (2004). The Surface of Articular Cartilage Contains a Progenitor Cell Population. J. Cel Sci 117, 889-897. doi:10.1242/jcs.00912

Dutton, A. Q., Choong, P. F., Goh, J. C., Lee, E. H., and Hui, J. H. (2010), Enhancement of Meniscal Repair in the Avascular Zone Using Mesenchymal Stem Cells in a Porcine Model. J. Bone Jt. Surg Br 92 (1), 169-175. doi:10.1302/ 0301-620X.92B1.22629

Embree, M. C., Chen, M., Pylawka, S., Kong, D., Iwaoka, G. M., Kalajzic, I., et al. (2016). Exploiting Endogenous Fibrocartilage Stem Cells to Regenerate Cartilage and Repair Joint Injury. Nat. Commun. 7, 13073. doi:10.1038/ ncomms13073

Englund, M., Roemer, F. W., Hayashi, D., Crema, M. D., and Guermazi, A. (2012). Meniscus Pathology, Osteoarthritis and the Treatment Controversy. Nat. Rev. Rheumatol. 8 (7), 412-419. doi:10.1038/nrrheum.2012.69

Esposito, A. R., Moda, M., Cattani, S. M. d. M., de Santana, G. M., Barbieri, J. A., Munhoz, M. M., et al. (2013). PLDLA/PCL-T Scaffold for Meniscus Tissue Engineering. BioResearch Open Access 2 (2), 138-147. doi:10.1089/biores.2012.0293

Fa, M., and Cook, J. L. (2017). Tissue-Derived Extracellular Matrix Bioscaffolds: Emerging Applications in Cartilage and Meniscus Repair. Tissue Eng. B, Rev. 23 (4), 386-398. doi:10.1089/ten.TEB.2016.0431

Ferris, D., Frisbie, D., Kisiday, J., and McIlwraith, C. W. (2012). In Vivo healing of Meniscal Lacerations Using Bone Marrow-Derived Mesenchymal Stem Cells and Fibrin Glue. Stem Cell Int 2012, 691605. doi:10.1155/2012/691605

Fischenich, K. M., Pauly, H. M., Lewis, J. T., Bailey, T. S., and Haut Donahue, T. L. (2018). A Hydrogel Meniscal Replacement: Knee Joint Pressure and Distribution in an Ovine Model Compared to Native Tissue. Ann. Biomed. Eng. 46 (11), 1785-1796. doi:10.1007/s10439-018-2069-8

Gamer, L. W., Shi, R. R., Gendelman, A., Mathewson, D., Gamer, J., and Rosen, V. (2017). Identification and Characterization of Adult Mouse Meniscus Stem/ progenitor Cells. Connect. Tissue Res. 58 (3-4), 238-245. doi:10.1080/03008207. 2016.1271797

Gastel, J. A., Muirhead, W. R., Lifrak, J. T., Fadale, P. D., Hulstyn, M. J., and Labrador, D. P. (2001). Meniscal Tissue Regeneration Using a Collagenous Biomaterial Derived from Porcine Small Intestine Submucosa. Arthrosc. J. Arthroscopic Relat. Surg. 17 (2), 151-159. doi:10.1053/jars.2001.20959 
Ghodbane, S. A., Brzezinski, A., Patel, J. M., Plaff, W. H., Marzano, K. N., Gatt, C. J., et al. (2019). Partial Meniscus Replacement with a Collagen-Hyaluronan Infused Three-Dimensional Printed Polymeric Scaffold. Tissue Eng. Part. A. 25 (5-6), 379-389. doi:10.1089/ten.TEA.2018.0160

Ghodbane, S. A., Patel, J. M., Brzezinski, A., Lu, T. M., Gatt, C. J., and Dunn, M. G. (2019). Biomechanical Characterization of a Novel Collagen-Hyaluronan Infused 3D-Printed Polymeric Device for Partial Meniscus Replacement. J. Biomed. Mater. Res. B Appl. Biomater. 107, 2457. doi:10.1002/jbm.b.34336

Grogan, S. P., Barbero, A., Diaz-Romero, J., Cleton-Jansen, A.-M., Soeder, S., Whiteside, R., et al. (2007). Identification of Markers to Characterize and Sort Human Articular Chondrocytes with Enhanced In Vitro Chondrogenic Capacity. Arthritis Rheum. 56 (2), 586-595. doi:10.1002/art.22408

Guo, W., Xu, W., Wang, Z., Chen, M., Hao, C., Zheng, X., et al. (2018). Cell-Free Strategies for Repair and Regeneration of Meniscus Injuries through the Recruitment of Endogenous Stem/Progenitor Cells. Stem Cell Int 2018, 5310471. doi:10.1155/2018/5310471

Gwinner, C., Von Roth, P., Schmidt, S., Ode, J. E., Wulsten, D., and Hoburg, A. (2017). Biomechanical Performance of a Collagen Meniscus Implant with Regard to Suture Material and Irrigation Fluid. Knee 24 (4), 726-732. doi:10.1016/j.knee.2017.04.003

Hatsushika, D., Muneta, T., Nakamura, T., Horie, M., Koga, H., Nakagawa, Y., et al. (2014). Repetitive Allogeneic Intraarticular Injections of Synovial Mesenchymal Stem Cells Promote Meniscus Regeneration in a Porcine Massive Meniscus Defect Model. Osteoarthritis and Cartilage 22 (7), 941-950. doi:10.1016/j.joca. 2014.04.028

Hiraoka, K., Grogan, S., Olee, T., and Lotz, M. (2006). Mesenchymal Progenitor Cells in Adult Human Articular Cartilage. Biorheology 43 (3), 447-454.

Horie, M., Choi, H., Lee, R. H., Reger, R. L., Ylostalo, J., Muneta, T., et al. (2012). Intra-articular Injection of Human Mesenchymal Stem Cells (MSCs) Promote Rat Meniscal Regeneration by Being Activated to Express Indian Hedgehog that Enhances Expression of Type II Collagen. Osteoarthritis and Cartilage 20 (10), 1197-1207. doi:10.1016/j.joca.2012.06.002

Horie, M., Driscoll, M. D., Sampson, H. W., Sekiya, I., Caroom, C. T., Prockop, D. J., et al. (2012). Implantation of Allogenic Synovial Stem Cells Promotes Meniscal Regeneration in a Rabbit Meniscal Defect Model. J. Bone Jt. Surg Am 94 (8), 701-712. doi:10.2106/jbjs.k.00176

Horie, M., Sekiya, I., Muneta, T., Ichinose, S., Matsumoto, K., Saito, H., et al. (2009). Intra-articular Injected Synovial Stem Cells Differentiate into Meniscal Cells Directly and Promote Meniscal Regeneration without Mobilization to Distant Organs in Rat Massive Meniscal Defect. Stem Cells 27 (4), 878-887. doi:10. 1634/stemcells.2008-0616

Isern, J., Martín-Antonio, B., Ghazanfari, R., Martín, A. M., López, J. A., del Toro, R., et al. (2013). Self-renewing Human Bone Marrow Mesenspheres Promote Hematopoietic Stem Cell Expansion. Cel Rep. 3 (5), 1714-1724. doi:10.1016/j. celrep.2013.03.041

Ishimura, M., Tamai, S., and Fujisawa, Y. (2000). Arthroscopic Meniscal Repair with Fibrin Glue. Oper. Techniquesin Orthopaedics 10 (3), 212-219. doi:10. 1016/0749-8063(91)90106-8

Izuta, Y., Ochi, M., Adachi, N., Deie, M., Yamasaki, T., and Shinomiya, R. (2005). Meniscal Repair Using Bone Marrow-Derived Mesenchymal Stem Cells: Experimental Study Using green Fluorescent Protein Transgenic Rats. The Knee 12 (3), 217-223. doi:10.1016/j.knee.2001.06.001

Jayasuriya, C. T., Twomey-Kozak, J., Newberry, J., Desai, S., Feltman, P., Franco, J. R., et al. (2019). Human Cartilage-Derived Progenitors Resist Terminal Differentiation and Require CXCR4 Activation to Successfully Bridge Meniscus Tissue Tears. Stem Cells 37 (1), 102-114. doi:10.1002/stem.2923

Jo, C. H., Ahn, H. J., Kim, H. J., Seong, S. C., and Lee, M. C. (2007). Surface Characterization and Chondrogenic Differentiation of Mesenchymal Stromal Cells Derived from Synovium. Cytotherapy 9 (4), 316-327. doi:10.1080/ 14653240701291620

Kang, S.-W., Sun-Mi, S., Jae-Sun, L., Eung-Seok, L., Kwon-Yong, L., Sang-Guk, P., et al. (2006). Regeneration of Whole Meniscus Using Meniscal Cells and Polymer Scaffolds in a Rabbit Total Meniscectomy Model. J. Biomed. Mater. Res. 77A (4), 659-671. doi:10.1002/jbm.a.30579

Katagiri, H., Muneta, T., Tsuji, K., Horie, M., Koga, H., Ozeki, N., et al. (2013). Transplantation of Aggregates of Synovial Mesenchymal Stem Cells Regenerates Meniscus More Effectively in a Rat Massive Meniscal Defect.
Biochem. Biophysical Res. Commun. 435 (4), 603-609. doi:10.1016/j.bbrc.2013. 05.026

Kelly, B. T., Robertson, W., Potter, H. G., Deng, X.-H., Turner, A. S., Lyman, S., et al. (2007). Hydrogel Meniscal Replacement in the Sheep Knee. Am. J. Sports Med. 35 (1), 43-52. doi:10.1177/0363546506292848

Koch, M., Achatz, F. P., Lang, S., Pfeifer, C. G., Pattappa, G., Kujat, R., et al. (2018). Tissue Engineering of Large Full-Size Meniscus Defects by a Polyurethane Scaffold: Accelerated Regeneration by Mesenchymal Stromal Cells. Stem Cell Int 2018, 8207071. doi:10.1155/2018/8207071

Koh, R. H., Jin, Y., Kang, B.-J., and Hwang, N. S. (2017). Chondrogenically Primed Tonsil-Derived Mesenchymal Stem Cells Encapsulated in Riboflavin-Induced Photocrosslinking Collagen-Hyaluronic Acid Hydrogel for Meniscus Tissue Repairs. Acta Biomater. 53, 318-328. doi:10.1016/j.actbio.2017.01.081

Koller, U., Nehrer, S., Vavken, P., Kapeller, B., Windhager, R., and Chiari, C. (2012). Polyethylene Terephthalate (PET) Enhances Chondrogenic Differentiation of Ovine Meniscocytes in a Hyaluronic Acid/ polycaprolactone Scaffold In Vitro. Int. Orthopaedics (Sicot) 36 (9), 1953-1960. doi:10.1007/s00264-012-1534-5

Kondo, S., Muneta, T., Nakagawa, Y., Koga, H., Watanabe, T., Tsuji, K., et al. (2017). Transplantation of Autologous Synovial Mesenchymal Stem Cells Promotes Meniscus Regeneration in Aged Primates. J. orthopaedic researchofficial Publ. Orthopaedic Res. Soc. 35 (6), 1274-1282. doi:10.1002/ jor.23211

Kremer, A., Ribitsch, I., Reboredo, J., Dürr, J., Egerbacher, M., Jenner, F., et al. (2017). Three-Dimensional Coculture of Meniscal Cells and Mesenchymal Stem Cells in Collagen Type I Hydrogel on a Small Intestinal Matrix-A Pilot Study toward Equine Meniscus Tissue Engineering. Tissue Eng. Part. A. 23 (910), 390-402. doi:10.1089/ten.TEA.2016.0317

Kurzweil, P. R., Cannon, W. D., and DeHaven, K. E. (2018). Meniscus Repair and Replacement. Sports Med. Arthrosc. 26 (4), 160-164. doi:10.1097/jsa. 0000000000000224

Lee, C. H., Rodeo, S. A., Fortier, L. A., Lu, C., Erisken, C., and Mao, J. J. (2014). Protein-releasing Polymeric Scaffolds Induce Fibrochondrocytic Differentiation of Endogenous Cells for Knee Meniscus Regeneration in Sheep. Sci. Transl Med. 6 (6), 266ra171. doi:10.1126/scitranslmed.3009696

Li, H., Li, P., Yang, Z., Gao, C., Fu, L., Liao, Z., et al. (2021). Meniscal Regenerative Scaffolds Based on Biopolymers and Polymers: Recent Status and Applications. Front. Cel Dev. Biol. 9, 661802. doi:10.3389/fcell.2021.661802

Liu, H., Wei, X., Ding, X., Li, X., Zhou, G., Li, P., et al. (2015). Comparison of Cellular Responses of Mesenchymal Stem Cells Derived from Bone Marrow and Synovium on Combined Silk Scaffolds. J. Biomed. Mater. Res. 103 (1), 115-125. doi:10.1002/jbm.a.35154

López-Calzada, G., Hernandez-Martínez, A. R., Cruz-Soto, M., Ramírez-Cardona, M., Rangel, D., Molina, G. A., et al. (2016). Development of Meniscus Substitutes Using a Mixture of Biocompatible Polymers and Extra Cellular Matrix Components by Electrospinning. Mater. Sci. Eng. C 61, 893-905. doi:10. 1016/j.msec.2016.01.018

Ma, Q., Liao, J., and Cai, X. (2018). Different Sources of Stem Cells and Their Application in Cartilage Tissue Engineering. Cscr 13 (7), 568-575. doi:10.2174/ 1574888x13666180122151909

Mabuchi, Y., Morikawa, S., Harada, S., Niibe, K., Suzuki, S., Renault-Mihara, F., et al. (2013). LNGFR+THY-1+VCAM-1hi+ Cells Reveal Functionally Distinct Subpopulations in Mesenchymal Stem Cells. Stem Cel. Rep. 1 (2), 152-165. doi:10.1016/j.stemcr.2013.06.001

Makris, E. A., Hadidi, P., and Athanasiou, K. A. (2011). The Knee Meniscus: Structure-Function, Pathophysiology, Current Repair Techniques, and Prospects for Regeneration. Biomaterials 32 (30), 7411-7431. doi:10.1016/j. biomaterials.2011.06.037

Mandal, B. B., Park, S.-H., Gil, E. S., and Kaplan, D. L. (2011). Multilayered Silk Scaffolds for Meniscus Tissue Engineering. Biomaterials 32 (2), 639-651. doi:10.1016/j.biomaterials.2010.08.115

Marom, N., Ode, G., Coxe, F., Jivanelli, B., and Rodeo, S. A. (2021). Current Concepts on Tissue Adhesive Use for Meniscal Repair-We Are Not There yet: A Systematic Review of the Literature. Am. J. Sports Med., 3635465211003613. doi:10.1177/03635465211003613

Matsumura, E., Tsuji, K., Komori, K., Koga, H., Sekiya, I., and Muneta, T. (2017). Pretreatment with IL-1 $\beta$ Enhances Proliferation and Chondrogenic Potential of 
Synovium-Derived Mesenchymal Stem Cells. Cytotherapy 19 (2), 181-193. doi:10.1016/j.jcyt.2016.11.004

Matthies, N.-F., Mulet-Sierra, A., Jomha, N. M., and Adesida, A. B. (2013). Matrix Formation Is Enhanced in Co-cultures of Human Meniscus Cells with Bone Marrow Stromal Cells. J. Tissue Eng. Regen. Med. 7 (12), 965-973. doi:10.1002/ term. 1489

McCorry, M. C., Puetzer, J. L., and Bonassar, L. J. (2016). Characterization of Mesenchymal Stem Cells and Fibrochondrocytes in Three-Dimensional Coculture: Analysis of Cell Shape, Matrix Production, and Mechanical Performance. Stem Cel Res Ther 7, 39. doi:10.1186/s13287-016-0301-8

Merriam, A. R., Patel, J. M., Culp, B. M., Gatt, C. J., Jr., and Dunn, M. G. (2015). Successful Total Meniscus Reconstruction Using a Novel Fiber-Reinforced Scaffold. Am. J. Sports Med. 43 (10), 2528-2537. doi:10.1177/ 0363546515595065

Morejon, A., Norberg, C. D., De Rosa, M., Best, T. M., Jackson, A. R., and Travascio, F. (2020). Compressive Properties and Hydraulic Permeability of Human Meniscus: Relationships with Tissue Structure and Composition. Front. Bioeng. Biotechnol. 8, 622552. doi:10.3389/fbioe.2020.622552

Murakami, T., Otsuki, S., Nakagawa, K., Okamoto, Y., Inoue, T., Sakamoto, Y., et al. (2017). Establishment of Novel Meniscal Scaffold Structures Using Polyglycolic and Poly-L-Lactic Acids. J. Biomater. Appl. 32 (2), 150-161. doi:10.1177/0885328217713631

Nakagawa, Y., Muneta, T., Kondo, S., Mizuno, M., Takakuda, K., Ichinose, S., et al. (2015). Synovial Mesenchymal Stem Cells Promote Healing after Meniscal Repair in Microminipigs. Osteoarthritis and Cartilage 23 (6), 1007-1017. doi:10.1016/j.joca.2015.02.008

Osawa, A., Harner, C. D., Gharaibeh, B., Matsumoto, T., Mifune, Y., Kopf, S., et al. (2013). The Use of Blood Vessel-Derived Stem Cells for Meniscal Regeneration and Repair. Med. Sci. Sports Exerc. 45 (5), 813-823. doi:10.1249/mss. 0b013e31827d1e06

Pabbruwe, M. B., Kafienah, W., Tarlton, J. F., Mistry, S., Fox, D. J., and Hollander, A. P. (2010). Repair of Meniscal Cartilage white Zone Tears Using a Stem Cell/ collagen-Scaffold Implant. Biomaterials 31 (9), 2583-2591. doi:10.1016/j. biomaterials.2009.12.023

Pinho, S., Lacombe, J., Hanoun, M., Mizoguchi, T., Bruns, I., Kunisaki, Y., et al. (2013). PDGFRa and CD51 Mark Human Nestin+ Sphere-Forming Mesenchymal Stem Cells Capable of Hematopoietic Progenitor Cell Expansion. J. Exp. Med. 210 (7), 1351-1367. doi:10.1084/jem.20122252

Port, J., Jackson, D. W., Lee, T. Q., and Simon, T. M. (1996). Meniscal Repair Supplemented with Exogenous Fibrin Clot and Autogenous Cultured Marrow Cells in the Goat Model. Am. J. Sports Med. 24 (4), 547-555. doi:10.1177/ 036354659602400422

Puetzer, J. L., Brown, B. N., Ballyns, J. J., and Bonassar, L. J. (2013). The Effect of IGF-I on Anatomically Shaped Tissue-Engineered Menisci. Tissue Eng. Part. A. 19 (11-12), 1443-1450. doi:10.1089/ten.TEA.2012.0645

Qi, Y., Yang, Z., Ding, Q., Zhao, T., Huang, Z., and Feng, G. (2016). Targeted Transplantation of Iron Oxide-Labeled, Adipose-Derived Mesenchymal Stem Cells in Promoting Meniscus Regeneration Following a Rabbit Massive Meniscal Defect. Exp. Ther. Med. 11 (2), 458-466. doi:10.3892/etm.2015.2944

Roche, S., Delorme, B., Oostendorp, R. A. J., Barbet, R., Caton, D., Noel, D., et al. (2009). Comparative Proteomic Analysis of Human Mesenchymal and Embryonic Stem Cells: towards the Definition of a Mesenchymal Stem Cell Proteomic Signature. Proteomics 9 (2), 223-232. doi:10.1002/pmic.200800035

Rongen, J. J., van Tienen, T. G., van Bochove, B., Grijpma, D. W., and Buma, P. (2014). Biomaterials in Search of a Meniscus Substitute. Biomaterials 35 (11), 3527-3540. doi:10.1016/j.biomaterials.2014.01.017

Ruiz-Ibán, M. Á., Díaz-Heredia, J., García-Gómez, I., Gonzalez-Lizán, F., ElíasMartín, E., and Abraira, V. (2011). The Effect of the Addition of AdiposeDerived Mesenchymal Stem Cells to a Meniscal Repair in the Avascular Zone: an Experimental Study in Rabbits. Arthrosc. J. Arthroscopic Relat. Surg. 27 (12), 1688-1696. doi:10.1016/j.arthro.2011.06.041

Sakaguchi, Y., Sekiya, I., Yagishita, K., and Muneta, T. (2005). Comparison of Human Stem Cells Derived from Various Mesenchymal Tissues: Superiority of Synovium as a Cell Source. Arthritis Rheum. 52 (8), 2521-2529. doi:10.1002/art. 21212

Saltzman, B. M., Meyer, M. A., Weber, A. E., Poland, S. G., Yanke, A. B., and Cole, B. J. (2017). Prospective Clinical and Radiographic Outcomes after Concomitant Anterior Cruciate Ligament Reconstruction and Meniscal
Allograft Transplantation at a Mean 5-Year Follow-Up. Am. J. Sports Med. 45 (3), 550-562. doi:10.1177/0363546516669934

Seol, D., Zhou, C., Brouillette, M. J., Song, I., Yu, Y., Choe, H. H., et al. (2017). Characteristics of Meniscus Progenitor Cells Migrated from Injured Meniscus. J. Orthop. Res. 35 (9), 1966-1972. doi:10.1002/jor.23472

Shen, W., Chen, J., Zhu, T., Chen, L., Zhang, W., Fang, Z., et al. (2014). Intraarticular Injection of Human Meniscus Stem/progenitor Cells Promotes Meniscus Regeneration and Ameliorates Osteoarthritis through Stromal Cell-Derived Factor-1/cxcr4-Mediated Homing. Stem Cell Transl Med 3 (3), 387-394. doi:10.5966/sctm.2012-0170

Shen, W., Chen, J., Zhu, T., Yin, Z., Chen, X., Chen, L., et al. (2013). Osteoarthritis Prevention through Meniscal Regeneration Induced by Intra-articular Injection of Meniscus Stem Cells. Stem Cell Dev. 22 (14), 2071-2082. doi:10.1089/scd. 2012.0563

Shi, W., Sun, M., Hu, X., Ren, B., Cheng, J., Li, C., et al. (2017). Structurally and Functionally Optimized Silk-Fibroin-Gelatin Scaffold Using 3D Printing to Repair Cartilage Injury In Vitro and In Vivo. Adv. Mater. 29 (29). doi:10.1002/ adma.201701089

Shimomura, K., Rothrauff, B. B., and Tuan, R. S. (2017). Region-Specific Effect of the Decellularized Meniscus Extracellular Matrix on Mesenchymal Stem CellBased Meniscus Tissue Engineering. Am. J. Sports Med. 45 (3), 604-611. doi:10. $1177 / 0363546516674184$

Slaughter, B. V., Khurshid, S. S., Fisher, O. Z., Khademhosseini, A., and Peppas, N. A. (2009). Hydrogels in Regenerative Medicine. Adv. Mater. 21 (32-33), 3307-3329. doi:10.1002/adma.200802106

Sonoda, M., Harwood, F. L., Amiel, M. E., Moriya, H., Temple, M., Chang, D. G., et al. (2000). The Effects of Hyaluronan on Tissue Healing after Meniscus Injury and Repair in a Rabbit Model. Am. J. Sports Med. 28 (1), 90-97. doi:10.1177/ 03635465000280012801

Strem, B. M., Hicok, K. C., Zhu, M., Wulur, I., Alfonso, Z., Schreiber, R. E., et al. (2005). Multipotential Differentiation of Adipose Tissue-Derived Stem Cells. Keio J. Med. 54 (3), 132-141. doi:10.2302/kjm.54.132

Sun, H., Wen, X., Li, H., Wu, P., Gu, M., Zhao, X., et al. (2020). Single-cell RNA-Seq Analysis Identifies Meniscus Progenitors and Reveals the Progression of Meniscus Degeneration. Ann. Rheum. Dis. 79 (3), 408-417. doi:10.1136/ annrheumdis-2019-215926

Szojka, A., Lalh, K., Andrews, S. H. J., Jomha, N. M., Osswald, M., and Adesida, A. B. (2017). Biomimetic 3D Printed Scaffolds for Meniscus Tissue Engineering. Bioprinting 8, 1-7. doi:10.1016/j.bprint.2017.08.001

Tan, Y., Zhang, Y., and Pei, M. (2010). Meniscus Reconstruction through Coculturing Meniscus Cells with Synovium-Derived Stem Cells on Small Intestine Submucosa-A Pilot Study to Engineer Meniscus Tissue Constructs. Tissue Eng. A 16 (1), 67-79. doi:10.1089/ten.tea.2008.0680

Tanaka, Y., Yamaoka, H., Nishizawa, S., Nagata, S., Ogasawara, T., Asawa, Y., et al. (2010). The Optimization of Porous Polymeric Scaffolds for Chondrocyte/ atelocollagen Based Tissue-Engineered Cartilage. Biomaterials 31 (16), 4506-4516. doi:10.1016/j.biomaterials.2010.02.028

Tarafder, S., Gulko, J., Sim, K. H., Yang, J., Cook, J. L., and Lee, C. H. (2018). Engineered Healing of Avascular Meniscus Tears by Stem Cell Recruitment. Sci. Rep. 8 (1), 8150. doi:10.1038/s41598-018-26545-8

Toratani, T., Nakase, J., Numata, H., Oshima, T., Takata, Y., Nakayama, K., et al. (2017). Scaffold-Free Tissue-Engineered Allogenic Adipose-Derived Stem Cells Promote Meniscus Healing. Arthrosc. J. Arthroscopic Relat. Surg. 33 (2), 346-354. doi:10.1016/j.arthro.2016.07.015

Toratani, T., Nakase, J., Numata, H., Oshima, T., Takata, Y., Nakayama, K., et al. (2017). Scaffold-Free Tissue-Engineered Allogenic Adipose-Derived Stem Cells Promote Meniscus Healing. Arthroscopy 33 (2), 346-354. doi:10.1016/j.arthro. 2016.07.015

Twomey-Kozak, J., and Jayasuriya, C. T. (2020). Meniscus Repair and Regeneration. Clin. Sports Med. 39 (1), 125-163. doi:10.1016/j.csm.2019.08.003

Wang, Y., Rudym, D. D., Walsh, A., Abrahamsen, L., Kim, H. J., Kim, H. S., et al. (2008). In Vivo degradation of Three-Dimensional Silk Fibroin Scaffolds. Biomaterials 29 (24-25), 3415-3428. doi:10.1016/j.biomaterials.2008.05.002

Weiss, W. M., Mulet-Sierra, A., Kunze, M., Jomha, N. M., and Adesida, A. B. (2017). Coculture of Meniscus Cells and Mesenchymal Stem Cells in Simulated Microgravity. NPJ Microgravity 3, 28. doi:10.1038/s41526-017-0032-x

Welsing, R. T. C., van Tienen, T. G., Ramrattan, N., Heijkants, R., Schouten, A. J., Veth, R. P. H., et al. (2008). Effect on Tissue Differentiation and Articular 
Cartilage Degradation of a Polymer Meniscus Implant. Am. J. Sports Med. 36 (10), 1978-1989. doi:10.1177/0363546508319900

Williams, D., Thayer, P., Martinez, H., Gatenholm, E., and Khademhosseini, A. (2018). A Perspective on the Physical, Mechanical and Biological Specifications of Bioinks and the Development of Functional Tissues in 3D Bioprinting. Bioprinting 9, 19-36. doi:10.1016/j.bprint.2018.02.003

Xie, X., Zhu, J., Hu, X., Dai, L., Fu, X., Zhang, J., et al. (2018). A Co-culture System of Rat Synovial Stem Cells and Meniscus Cells Promotes Cell Proliferation and Differentiation as Compared to Mono-Culture. Sci. Rep. 8 (1), 7693. doi:10. 1038/s41598-018-25709-w

Xue, K., Xia, W., Zhang, X., Qi, L., Zhou, J., Xu, P., et al. (2015). Isolation and Identification of Stem Cells in Different Subtype of Cartilage Tissue. Expert Opin. Biol. Ther. 15 (5), 623-632. doi:10.1517/14712598.2015.989207

Ying, X. Z., Qian, J. J., Peng, L., Zheng, Q., Zhu, B., and Jin, Y. H. (2018). Model Research on Repairing Meniscus Injury in Rabbits Using Bone Marrow Mesenchymal Stem Cells and Silk Fibroin Meniscus Porous Scaffold. Eur. Rev. Med. Pharmacol. Sci. 22 (12), 3689-3693. doi:10.26355/ eurrev_201806_15247

Yuan, X., Wei, Y., Villasante, A., Ng, J. J. D., Arkonac, D. E., Chao, P.-h. G., et al. (2017). Stem Cell Delivery in Tissue-specific Hydrogel Enabled Meniscal Repair in an Orthotopic Rat Model. Biomaterials 132, 59-71. doi:10.1016/j. biomaterials.2017.04.004

Zhang, Z.-Z., Jiang, D., Wang, S.-J., Qi, Y.-S., Ding, J.-X., Yu, J.-K., et al. (2015). Scaffolds Drive Meniscus Tissue Engineering. RSC Adv. 5 (95), 77851-77859. doi:10.1039/c5ra13859k

Zhang, Z.-Z., Wang, S.-J., Zhang, J.-Y., Jiang, W.-B., Huang, A.-B., Qi, Y.-S., et al. (2017). 3D-Printed Poly( $\varepsilon$-Caprolactone) Scaffold Augmented with Mesenchymal Stem Cells for Total Meniscal Substitution: A 12- and 24Week Animal Study in a Rabbit Model. Am. J. Sports Med. 45 (7), 1497-1511. doi:10.1177/0363546517691513

Zhang, Z.-Z., Zhou, Y.--F., Luo, H., Zhang, H.-Z., Chen, Z., Jiang, C., et al. (2020). A Novel Surgical Technique for Arthroscopic Repair of Type II Posterior Lateral Meniscal Root Tear. The Knee 27 (5), 1560-1566. doi:10.1016/j.knee.2020. 07.100
Zhang, Z. Z., Chen, Y. R., Wang, S. J., Zhao, F., Wang, X. G., Yang, F., et al. (2019). Orchestrated Biomechanical, Structural, and Biochemical Stimuli for Engineering Anisotropic Meniscus. Sci. Transl Med. 11 (487), eaao0750. doi:10.1126/scitranslmed.aao0750

Zhong, G., Yao, J., Huang, X., Luo, Y., Wang, M., Han, J., et al. (2020). Injectable ECM Hydrogel for Delivery of BMSCs Enabled Full-Thickness Meniscus Repair in an Orthotopic Rat Model. Bioactive Mater. 5 (4), 871-879. doi:10.1016/j. bioactmat.2020.06.008

Zhu, J., and Marchant, R. E. (2011). Design Properties of Hydrogel Tissue-Engineering Scaffolds. Expert Rev. Med. Devices 8 (5), 607-626. doi:10.1586/erd.11.27

Zuk, P. A., Zhu, M., Ashjian, P., De Ugarte, D. A., Huang, J. I., Mizuno, H., et al. (2002). Human Adipose Tissue Is a Source of Multipotent Stem Cells. MBoC 13 (12), 4279-4295. doi:10.1091/mbc.e02-02-0105

Zuk, P. A., Zhu, M., Mizuno, H., Huang, J., Futrell, J. W., Katz, A. J., et al. (2001). Multilineage Cells from Human Adipose Tissue: Implications for Cell-Based Therapies. Tissue Eng. 7 (2), 211-228. doi:10.1089/107632701300062859

Conflict of Interest: The authors declare that the research was conducted in the absence of any commercial or financial relationships that could be construed as a potential conflict of interest.

Publisher's Note: All claims expressed in this article are solely those of the authors and do not necessarily represent those of their affiliated organizations, or those of the publisher, the editors, and the reviewers. Any product that may be evaluated in this article, or claim that may be made by its manufacturer, is not guaranteed or endorsed by the publisher.

Copyright $\odot 2022$ Zhou, Zhang, Yan, Lian and Zhang. This is an open-access article distributed under the terms of the Creative Commons Attribution License (CC BY). The use, distribution or reproduction in other forums is permitted, provided the original author(s) and the copyright owner(s) are credited and that the original publication in this journal is cited, in accordance with accepted academic practice. No use, distribution or reproduction is permitted which does not comply with these terms. 